\title{
Notas sobre la evolución del conocimiento administrativo en la República Argentina y su comparación con el caso español (1913-2007)
}

\author{
Notes on the evolution of management knowledge in Argentina with a \\ comparison to the Spanish case (1913-2007)
}

\author{
Ernesto R. Gantman ${ }^{1}$ \\ Carlos Jesús Fernández Rodrígueź
}

\begin{abstract}
Resumen
El presente estudio presenta una reconstrucción histórica comparativa de la administración como disciplina académica en la República Argentina y España, dos países con algunas características similares lingüísticas e institucionales, propias de la relación metrópoli-colonia, pero signados por distintas trayectorias de desarrollo. El análisis realizado revela importantes paralelismos. En primer lugar, ambos países son claros "importadores" de conocimiento administrativo, especialmente de desarrollos originados en los Estados Unidos, algo que probablemente se deba a las posiciones que históricamente han tenido en el sistema capitalista mundial. En segundo lugar, la disciplina evidencia una orientación marcadamente profesionalista y la generación del conocimiento original más riguroso, propio de la literatura organizacional y administrativa de índole científica, parece carecer de importancia.
\end{abstract}

Palavras-chave: Argentina; España; conocimiento administrativo; historia de la administración

Abstract

This paper presents a comparative historical reconstruction of the evolution of the management discipline in Argentina and Spain - two countries that share common institutional and linguistic characteristics, which derive from their colonial relationship, but differ in terms of their economic development paths. We conclude that there are important parallels in both cases. First, the two countries have a role of "importers" of management knowledge, particularly from the United States, which may result from the positions that they have historically occupied in the capitalist world system. Second, the discipline is dominated by a clearly professionalist orientation, and the production of academic management knowledge seems to have little importance.

Keywords: Argentina; Spain; management knowledge; management history

\footnotetext{
${ }^{1}$ Doctor de la Universidad de Buenos Aires (Administración). Profesor de La Universidade de Buenos Aires y Univ. de Belgrano. Ubicación: EENI - Univ de Belgrano, M. T. de Alvear 1560 - Capital Federal. CEP: 1060 - Argentina. Email: egantman@ub.eu.ar

${ }^{2}$ Doctor en Sociología (Univ. Autónoma de Madrid. )Profesor de Universidad Autónoma de Madrid. Ubicación: Dpto. de Sociología, Fac de CC. Econ, UNIV. AUT. DE MADRID - Campus de Cantoblanco - Madrid/España - CEP: 28049. Email: carlos.fernandez@uam.es

Artigo submetido em outubro de 2007 e aceito em aneiro
} 


\section{Introducción}

El estudio de la producción, difusión y consumo de conocimiento administrativo ha gozado de bastante atención académica en países desarrollados (Guillén, 1994: Álvarez, 1997: Sahlin-Andersson y Engwall, 2002). Sin embargo, y pese a algunas excepciones (Usdiken, 1997; 2004), existe mucha menos información sobre dichos procesos en países periféricos o subdesarrollados. Más importante aún, no hay estudios comparativos que exploren las razones de las diferencias entre países desarrollados y subdesarrollados, así como entre estos últimos entre sí. El presente documento apunta a brindar algunas precisiones sobre el caso argentino, realizando asimismo un comentario sobre la configuración del caso español. Dicha comparación resulta interesante por tratarse de dos países con algunas características similares lingüísticas e institucionales (propias de la relación metrópoli-colonia), pero signados por distintas trayectorias de desarrollo.

En primer lugar, es pertinente aclarar cuál será el foco principal de análisis en este trabajo, ya que la noción de conocimiento administrativo se asocia a múltiples manifestaciones que abarcan tanto las rutinas empresarias como la producción bibliográfica especializada. El objeto principal de estudio será aquí el conocimiento administrativo como disciplina académica y, por lo tanto, la investigación estará centrada en el conocimiento escrito sobre la gestión de organizaciones que se difunde principal, pero no exclusivamente, en circuitos universitarios. Específicamente, entonces, el trabajo se focaliza en un corpus disciplinario de artículos y libros cuyo objeto de análisis es la manera de organizar el trabajo humano en el contexto de organizaciones formales.

Adicionalmente, y dada la tradicional división entre administración pública y administración de negocios, debemos señalar que nos ocuparemos principalmente de esta última. ${ }^{1}$ Se excluyen también disciplinas relacionadas con la administración (contabilidad, marketing, finanzas) a las que algunos autores conceptualizan como "subespecialidades" de la misma.

El conocimiento administrativo no circula en el vacío, sino que es influenciado en diversos grados por factores sociales, políticos y económicos. En principio, es importante prestar atención a las características de las universidades e instituciones en las que éste es generado y difundido. Pero también se debe examinar el contexto general nacional e internacional, que condiciona no sólo a las universidades locales sino más directamente al tipo de conocimiento administrativo que se genera en éstas y en otras instituciones como firmas de consultoría, organizaciones empresarias, etc. Atento a esto, el trabajo se estructura de la siguiente manera. Una primera sección ofrece un breve repaso de la evolución del contexto político, económico e institucional del país durante el período de referencia ${ }^{2}$. La segunda sección expone en forma muy sucinta los puntos salientes del desarrollo del conocimiento administrativo en Argentina y, cuando resulta pertinente, se vinculan características propias de dicho conocimiento al contexto sociopolítico presentado en la sección anterior. Se destacan las contribuciones de los principales autores locales y se discute cómo han sido influenciados por el pensamiento foráneo dominante. Además, se exponen las características relevantes de las instituciones de educación superior en administración en el país, ya que es en ellas donde la producción y difusión del conocimiento administrativo tiene lugar. La tercera sección se centra en el caso español, con el que el argentino comparte ciertas similitudes, prestando atención a los principales actores detrás del desarrollo del conocimiento administrativo en dicho país. Por último, la conclusión resume los principales puntos del trabajo.

\section{El caso argentino (1913-2007)}

\subsection{El entorno político-institucional}

A principios del siglo XX, la República Argentina era considerada un país con amplio potencial de progreso (Lewis, 1993), cuya inserción en el sistema económico mundial como exportador de productos agropecuarios había brindado importantes beneficios a la clase terrateniente. La orientación político-económica dominante era de tipo liberal. La economía se basaba en la exportación de productos primarios, en razón de la ventaja comparativa que gozaba el país en materia agropecuaria, y la importación de productos manufacturados. El 
Estado se ocupaba fundamentalmente de garantizar el orden y el progreso, absteniéndose de intervenir en la economía. En 1930, una revolución militar depuso al presidente en ejercicio e inició un cambio de rumbo, procurando otorgar un mayor protagonismo al Estado en el manejo de la economía del país. Los gobiernos civiles que le sucedieron, asociados a las facciones dominantes de la llamada "oligarquía agro-exportadora", persistieron, no obstante, en mantener una política de corte liberal, aunque con un incipiente intervencionismo que realmente no atentaba contra los privilegios económicos de los sectores más beneficiados del régimen liberal, constituyendo una suerte de revolución "desde arriba" que intentaba modernizar e industrializar el país. Un nuevo golpe militar tuvo lugar en 1943, derrocando al gobierno civil de turno y dando inicio a un período en el que el Estado adquiere un considerable peso en la economía, etapa que llega a su expresión más acabada cuando uno de estos militares, Juan Domingo Perón, obtiene en elecciones libres a la presidencia de la República.

Dos temas fueron centrales en el período 1900-1943. El primero de ellos es el atraso del país en materia industrial y el segundo el "problema social". En relación al problema del atraso industrial, cabe señalar que la orientación liberal del gobierno era contraria a la protección de aquellas industrias en las cuales el país no poseía una ventaja comparativa. En opinión de los pensadores liberales de la época, la protección industrial en Argentina sólo podía dar lugar a la creación de una "industria de invernadero", excepto para las industrias derivadas del agro, en las que sí hubo algunos avances en las primeras décadas del siglo XX. El país poseía pocos establecimientos industriales, los cuales además empleaban muy poca mano de obra: menos de 12 personas promedio en la década del treinta (Lewis, 1993). Las empresas más grandes estaban mayormente en manos de capital extranjero y se dedicaban a la provisión de servicios de infraestructura como transporte, energía y telecomunicaciones. No obstante, y contrariamente a la tesis de que el espíritu empresario no se destacaba en la Argentina de principios de siglo, hay que destacar que varios capitalistas locales, muchos de ellos inmigrantes o hijos de inmigrantes, habían logrado exitosamente desarrollar emprendimientos industriales en diversas áreas (alimentos, seguros, finanzas, etc.).

La cuestión social era el otro tema candente en la época. Las condiciones de vida de los trabajadores eran bastante malas, como señala un estudio de la Secretaría del Trabajo (Bialet-Massé, 1904). En este contexto, comenzaron a producirse fricciones entre obreros y patrones. Para muchos, el malestar social era el resultado de la prédica de anarquistas y otros indeseables que habían llegado desde Europa. En las fábricas, la acción de los sindicatos anarquistas intranquilizaba a los patrones. Al respecto, cabe mencionar que un grupo anarquista logró asesinar al Jefe de Policía en 1909. Otro hito en materia de violencia social fueron los hechos de la llamada "Semana Trágica" de 1919, cuando a causa de un llamamiento a una huelga en un taller metalúrgica se desataron actos de represión por parte de un grupo nacionalista, la "Liga Patriótica", que atacó los barrios de inmigrantes sospechados de anarquistas con un saldo que distintas fuentes estiman en 750 a 1500 muertos. De mayor gravedad fue la represión en 1920 de una huelga general producida en la Patagonia, que llevó al gobierno a requerir la intervención del ejército, situación que culminó con la muerte de 2000 obreros. Dado este grado de conflictividad, era obvio que los debates sobre empresas y organizaciones iban a ocuparse de la tensión social como tema excluyente.

A principios de la década del cuarenta la industria argentina había crecido y el nivel de vida de los trabajadores había aumentado en relación a las primeras décadas del siglo (Fillol, 1961). El gobierno civil en el poder, que abogaba por dar mayor ingerencia al Estado en la economía y contener el avance del sindicalismo, fue derrocado por un golpe militar. En el grupo militar que encabezó la insurgencia se destacaba Juan Domingo Perón como una de las figuras más importantes. Perón ocupó varios cargos durante este período militar. Fue Ministro de Guerra, Vicepresidente y Secretario de Trabajo. Desde esta última posición, logró varias cosas: (1) colocar hombres de confianza a la cabeza de algunos de los principales sindicatos, neutralizando la influencia de anarquistas y comunistas, y (2) implementar leyes sociales que otorgaban conquistas a la clase trabajadora, con lo cual se ganó la simpatía de dicho sector. Así, su poder dentro del gobierno comenzó paulatinamente a ampliarse. En 1946, Perón consiguió acceder en a la Presidencia de la República en elecciones en las cuales resultó victorioso por amplio margen, gracias al voto de los sectores de menores ingresos. A partir de entonces, inició su proyecto de instaurar un Estado corporativo con ingerencia en todas las actividades económicas, sociales y culturales del país. De acuerdo a Lewis (1993: 262), "como en la Italia fascista, tanto los sindicatos 
como el empresariado, las asociaciones profesionales, los estudiantes, los hombres de campo y los intelectuales habían quedado bajo el imperio de organizaciones controladas por el Estado".

Si bien la posición de Argentina al término de la Segunda Guerra Mundial era bastante favorable (un país semiindustrializado con una holgada posición financiera, al resultar acreedor frente al resto del mundo), de a poco comenzó a deteriorarse. Además de la creciente inflación y el incremento del gasto público, la industria atravesaba una crisis de productividad. Los opositores políticos al peronismo habían emigrado a Montevideo o habían sido encarcelados, pero no todos los argentinos aplaudían el régimen peronista. En los últimos años, había descontento incluso entre la Iglesia y sectores militares. Precisamente un grupo de militares disidentes inició una revolución que logra deponer a Perón en septiembre de 1955. La tarea de la llamada "Revolución Libertadora" consistió luego en regresar al país al cauce democrático y "desperonizarlo", para lo cual se proscribió al peronismo como partido político.

Entre 1955 y 1973 se sucedieron diversos gobiernos militares y democráticos. En lo político, Perón desde el exilio siguió teniendo ingerencia en la política argentina, por lo cual la desperonización fue un objetivo incumplido. En lo económico, el crecimiento del país fue muy lento y discontinuo. Tras el derrocamiento de Perón, los capitales extranjeros comenzaron a instalarse nuevamente en Argentina. La industria creció, pero comenzaron a diferenciarse claramente dos sectores: uno de firmas dinámicas, asociadas principalmente al capital extranjero, y otro de industrias poco competitivas de empresarios locales que pudieron desarrollarse al amparo del régimen de sustitución se importaciones (Lewis, 1993).

La eliminación de la proscripción del peronismo por parte de un gobierno militar saliente condujo a la victoria de un candidato del partido justicialista, expresión política de dicho movimiento, en las elecciones de 1973 y al retorno al país de Perón. Cámpora, el candidato triunfante del justicialismo, renunció al cargo y un nuevo llamamiento a elecciones legitimó por amplio margen a Perón como presidente en las urnas. Sin embargo, éste no logró ordenar la economía del país, en su intento por reeditar una política corporativista. La violencia política se desató con singular fuerza y amplios sectores de izquierda, algunos de los cuales fueron inicialmente integrantes del movimiento peronista, emprendieron la vía de la lucha armada. ${ }^{3}$. El fallecimiento de Perón en ejercicio del cargo fue un duro golpe para el partido. De cualquier modo, la economía ya estaba inmersa en una seria crisis con un elevado nivel de inflación. En 1976, un golpe militar se hizo cargo del gobierno con el manifiesto objetivo de restaurar el orden.

Durante el llamado "proceso de reorganización nacional", se combatió duramente a toda expresión de izquierda percibida como amenaza subversiva, con un saldo de 30.000 personas desaparecidas. La guerrilla armada fue eliminada, pero más difícil resultó la tarea de encauzar al país en la senda del crecimiento económico. A tal fin, se adoptó una política económica de corte liberal, al menos al nivel del discurso, que exaltaba la iniciativa privada y proponía restringir el peso del Estado en la economía. En la práctica, y quizás debido a la reticencia de la cúpula militar, la reducción del gasto público no fue sustancial y las principales empresas públicas continuaron en poder del Estado. La liberalización del comercio exterior y la sobrevaluación del peso tuvieron un efecto nefasto sobre la industria local, provocando una ola importante de cierre de empresas. A la deficiente performance en el plano económico se sumó la derrota militar en el intento del gobierno por recuperar las Islas Malvinas, en poder del Reino Unido. Estos dos factores combinados debilitaron severamente al régimen militar, lo cual precipitó la salida democrática en 1983.

Por primera vez el peronismo fue derrotado en las urnas y la democracia en el país se fue consolidando paulatinamente, pese a notorios problemas económicos que se tradujeron en dos episodios hiperinflacionarios (1989 y 1990). En 1989, el presidente radical, Raúl Alfonsín, cedió su lugar a Carlos Menem, un representante del partido justicialista que sorprendentemente abandonó el sesgo estatista que caracterizó a su partido para emprender un ambicioso proceso de liberalización y privatización de la economía. Su gestión estuvo acompañada de un boom de expectativas favorables. Muy lejos de la retórica nacionalista propia de dicho partido, que incluso había sido utilizada para bloquear los proyectos de privatización propuestos por el presidente Alfonsín en la última fase de su mandato, Menem emprendió una política internacional a la que uno de sus principales colaboradores calificó de "relaciones carnales" con los Estados Unidos. Tras ser reelecto en 
1995, fue derrotado en las elecciones de 1999. Su sucesor, el radical Fernando De la Rúa, que accedió al poder encabezando una alianza con otros partidos opositores al menemismo, debió hacer frente a la enorme deuda externa amasada durante la gestión de Menem. Final e inevitablemente, el país sucumbió ante una crisis financiera sin precedentes. Luego de una megadevaluación, que siguió a la renuncia del presidente De la Rúa en 2001, el país renegoció sus deudas y, con un entorno económico internacional más favorable, está actualmente atravesando una etapa de normalización de su economía.

\subsection{El entorno universitario y el conocimiento administrativo.}

Durante el período liberal u oligárquico, el conocimiento administrativo que se generó en el país fue muy escaso. Existía, empero, un interés en círculos gubernamentales y académicos por jerarquizar los estudios de las denominadas "ciencias mercantiles". En un país en el cual la universidad era, en opinión del destacado naturalista argentino Ángel Gallardo, esencialmente una "fábrica" de profesionales como ingenieros, abogados, y médicos (Camacho, 1971: 93) había ciertamente lugar para brindar status universitario a la profesión de contador público. Consistentemente con ello, y tras un par de años en los cuales la implementación del proyecto se demoró en las diversas esferas de decisión del gobierno nacional, se creó en 1913 la Facultad de Cs. Económicas (FCE) de la Universidad de Buenos Aires (UBA). Posteriormente, similares unidades se establecieron en otras universidades nacionales (González Rojas, 1988), pero el "centro de gravedad" de la creación y difusión de conocimiento administrativo se ubicó en Buenos Aires, ciudad capital y principal centro financiero y cultural del país, por lo cual la FCE de la UBA adquirió un protagonismo central.

Los primeros programas de estudios en dicha facultad se limitaban a la carrera de Contador Público y contemplaban un fuerte componente de enseñanza de la economía y el derecho, entendido como elemento esencial en la formación de profesionales en ciencias mercantiles.

En 1913 se inició en la FCE la publicación de lo que puede considerarse la primera revista académica argentina en su materia: la Revista de Ciencias Económicas (RCE), cuyos destinatarios eran esencialmente estudiantes y graduados. En su mayor parte se ocupaba de temas de economía. Con menor frecuencia se publicaban artículos de contabilidad y eran escasos los que trataban sobre la problemática de la gestión y las organizaciones. No obstante, en un país en el cual el "problema obrero" era una cuestión importante, no sorprende que los académicos dedicaran a las relaciones industriales alguna atención y la mayor parte de los pocos artículos sobre administración pertenecen a este tópico. En este sentido, debe mencionarse al académico y pensador socialista Alfredo Palacios, quien publicó en 1922 el libro La fatiga, algunos de cuyos capítulos aparecieron en la Revista de Ciencias Económicas, que dirigió durante algunos años.

En dicha obra, Palacios se revela como un acabado conocedor de la administración científica de F. W. Taylor, con quien discrepa en muchos aspectos, iniciando una línea de humanismo crítico que combina la ergonomía con la teoría política socialista. Su libro, que presenta análisis empíricos sobre los efectos que el trabajo produce en la atención y la salud de los obreros, fue galardonado con el Premio Nacional de Ciencias. Esta obra demuestra que los académicos argentinos no ignoraban los desarrollos internacionales más importantes de la administración. Con excepción del trabajo de Palacios, los desarrollos teóricos originales fueron escasos. Entre ellos, podemos mencionar también el trabajo de Arturo Hoyo (1922) respecto a las relaciones entre la cuestión obrera y el taylorismo. Además, cabe destacar que el tema de la gestión de fábricas por parte de sus trabajadores motivó incluso un informe de la Cámara de Diputados de la República Argentina (1923), publicado como Intervención de empleados y obreros en la gestión de empresas y fábricas.

La mayor parte de los conocimientos básicos sobre administración se difundían a través de manuales para universitarios, que incorporaban nociones de contabilidad, sistemas de información y organización de la industria y el comercio. Cabe asimismo señalar que, entre los libros destinados a textos de referencia básica sobre tales temas, la biblioteca de la facultad contaba con diversos trabajos escritos por autores españoles como Ruiz Soler 1924) y Sacristán y Zabala (1925).

Ya dijimos que la revolución militar de 1930 marcó un intento por otorgar al Estado un papel más activo en la economía y estimular el avance de la industria, pensamiento apoyado por muchos economistas de la época 
(e.g., Alejandro Bunge), pero no se evidencia ningún correlato entre este cambio de eje político-económico y el conocimiento administrativo que circula en la estructura universitaria argentina. Con el ascenso al poder de Perón, se generaron transformaciones en el sistema universitario. De acuerdo a Ciria y Sanguinetti (1987:117118), la política universitaria del peronismo tenía por objetivos: 1) "eliminar a los docentes opositores", independientemente de sus méritos académicos, 2) controlar a las autoridades universitarias, 3) difundir la doctrina peronista a través de agrupaciones estudiantiles que gozarán de apoyo oficial, y 4) "reprimir a los alumnos opositores con la violencia que resultase necesaria". Pese a la intervención del peronismo sobre la UBA, el ámbito académico se mantuvo esencialmente hostil al régimen.

En materia de desarrollos en pensamiento administrativo, el nivel de producción siguió siendo escaso. Quizás la publicación de carácter original más destacada posterior a 1930 y anterior al derrocamiento de Perón sea un trabajo de José A. Gilli (1944) titulado La fábrica. De Marx a Ford. En dicha obra, Gilli, nutriéndose de algunas categorías marxistas, desarrolla un análisis de las formas de producción en la industria a los efectos de explicar el surgimiento de la producción continua, que atribuye a Henry Ford. Dicho autor también dirige su atención, desde una perspectiva crítica, a los aportes de Taylor para incrementar la productividad del trabajador. Justamente, la administración científica de Taylor parece ser la teoría que mayor difusión tiene en el ámbito de las ciencias administrativas en el país. De hecho, en la década del cuarenta aparecieron las ediciones argentinas de la obra de Taylor, que antes circulaba a través de ediciones publicadas en España. ${ }^{4}$ Además, revelando una importante influencia de Taylor, encontramos trabajos como La organización científica del trabajo de G. Escudero (1942), y Racionalización Administrativa de Jacobo Wainer (1943), quien sería más adelante el primer rector de la Universidad Argentina de la Empresa. Recibió también atención el pensamiento de Henri Fayol, otro de los grandes clásicos de la administración, siendo justamente en Argentina donde se publicó en 1940, la primera traducción al castellano de su libro Administración Industrial y General.

El período 1946-1955 no resultó propicio ni para la introducción de teorías dominantes extranjeras (en particular la de las relaciones humanas, que entonces gozaba de auge en los Estados Unidos) ni para la generación de una escuela de pensamiento propio. Cabe mencionar, empero, la contribución de Juan Ernesto Llamazares (1955) con su obra Empresas modernas: ensayos sobre dirección y organización.

Con la normalización de la vida universitaria luego del derrocamiento de Perón, comenzó un período de auge para la universidad argentina, particularmente en las universidades públicas, que culminó hacia el año 1966 con actos de represión ejecutados por el gobierno militar de turno (la llamada "noche de los bastones largos"). Los vaivenes políticos hasta 1973, no obstante, no tuvieron mayor influencia en los estudios en administración, ya que los gobiernos militares buscaban evitar la difusión de posturas de ultraizquierda entre estudiantes y docentes, las cuales no tenían mayor cabida en la FCE de la UBA.

En dicha universidad se revisaron los programas vigentes y se creó la carrera de Licenciado en Administración en 1958. Las universidades privadas, cuyo funcionamiento fue autorizado en la segunda mitad de la década del cincuenta, también incluyeron esta carrera en la oferta de su plan de estudios. La primera institución en dictarla fue la Universidad Católica Argentina (Gónzalez Rojas, 1987).

A fines de la década del cincuenta, la FCE de la UBA firmó un convenio de colaboración académica con Columbia University y muchos docentes y graduados viajaron a perfeccionar su formación en dicha casa de estudios. Esto facilitó enormemente la importación a Argentina del "estado del arte" en teoría de la administración. Muchos de los llamados "Columbia boys" pasaron luego a integrar el plantel docente de la UBA y, en forma paralela, a desempeñar tareas de consultoría en los sectores público y privado. En la década del sesenta, regresaron de los Estados Unidos los integrantes de dicho grupo y comenzó una etapa de modernización del conocimiento administrativo.

Así, el taylorismo dejó de ser la visión dominante en administración y se incorporaron nuevas perspectivas. Ya entrados los años sesenta, se destacó particularmente la influencia de la teoría de la organización de Herbert Simon y la perspectiva de la teoría de los sistemas. La divulgación de estas corrientes se llevó a cabo en libros de texto cuyos autores eran en su casi absoluta mayoría docentes de la FCE de la UBA, que seguía siendo el centro más importante de generación de conocimiento administrativo del país. Muchos de los profesores en 
cuestión eran, además, consultores o funcionarios en empresas públicas o privadas (e.g., Vicente Perel, Pedro Pavesi, Federico Frischknecht, etc.).

El conocimiento administrativo se vio favorecido por la publicación de nuevos manuales introductorios. Entre ellos, deben mencionarse el Manual de administración y racionalización de empresas de Vicente L. Perel (1961), autor considerado una de las principales figuras de la disciplina en la FCE. ${ }^{5}$ Importante difusión alcanzó el Manual de administración de empresas publicado en 1963 por Manuel García Pazos y Federico Frischknecht. Precisamente este último, que fuera también decano de la FCE en 1966,_tuvo una destacada trayectoria como teórico de la administración en Argentina. En 1966, publicó la primera edición de La gerencia y la empresa, obra que se enmarca en la perspectiva de la teoría de la organización e incorpora el enfoque de la teoría de los sistemas. Frischknecht siguió desarrollando una línea de pensamiento bajo el marco de la teoría de sistemas en libros tales como Organización (1978) y, quizás una de las más originales, Dirección Recursiva (1993), que fuera su última obra. Su visión de la importancia de la teoría de sistemas para entender el comportamiento de las organizaciones quedó también plasmada en un artículo en colaboración publicado en un journal internacional (Frischknecht y Van Gigch, 1989). En sus respectivos campos, cabe también mencionar a autores como Pedro Pavesi en teoría de la decisión (Pavesi, 1963, Bagur et al., 1977) y Eduardo Luis Groba (1960) en administración de personal (ambos formados en la Universidad de Columbia).

Especialmente relevante ha sido también la obra de Bernardo Kliksberg, El pensamiento administrativo, basada en su tesis doctoral en la Universidad de la República (Uruguay) y cuya primera edición data de 1971. En este libro, Kliksberg dedica gran espacio a profundizar acerca del status científico de la administración y desarrolla una importante crítica tanto del taylorismo como de la escuela de las relaciones humanas. A diferencia de otros manuales, Kliksberg otorga gran importancia a la sociología industrial del francés Georges Friedmann para entender las organizaciones, rescatando también en su síntesis final algunos aportes de Simon, Pfiffer y Sherwood, y Stafford Beer.

El regreso del peronismo al poder y la violencia social que, lejos de apaciguarse, se incrementó en el período 1973-1976 tuvieron su efecto en las universidades argentinas. La ideología nacionalista y tercermundista que caracterizó al peronismo en dichos años tuvo un correlato no sólo en la politización de la vida universitaria argentina sino en la propia FCE de la UBA, que como señalamos no había sido afectada hasta el momento por los vaivenes de la política argentina. El Centro de Estudiantes de la FCE, por ejemplo, se hizo eco de esta tendencia nacionalista y pasó a denominarse Centro de Estudiantes por la Liberación Nacional. Los planes de estudio también cambiaron en 1973, siguiendo el clima ideológico imperante: se suprimieron algunas materias y se introdujeron otras como "Historia Nacional y Popular" (eliminada, no obstante, en 1975). Era común que la política universitaria invadiera las aulas y se realizaran "juicios a profesores" por sus actitudes en favor del imperialismo. Muchos prestigiosos profesores de la facultad renunciaron a sus cargos o fueron objetos de purgas por su vinculación profesional con empresas transnacionales o con grandes grupos empresarios locales. En lo académico, era una época de predominio del pensamiento de izquierda y de la teoría de la dependencia. Por cierto, no faltaban disputas entre grupos nacionalistas de derecha y sectores de izquierda, extremos ambos que se habían asociado al peronismo en dichos años a partir de los elementos centrales que los unían: el nacionalismo, su búsqueda del apoyo de los sectores populares, a los que aspiraban a representar, y su hostilidad hacia el imperialismo estadounidense.

El clima ideológico era propicio para la generación de un pensamiento crítico propio de carácter nacional (y podríamos agregar "popular", ya que ambos adjetivos solían ser utilizados en conjunto por los pensadores de la época), pero no ocurrió así en la disciplina de la administración, típicamente orientada a brindar soluciones prácticas a problemas empresarios. Podemos señalar, como excepciones dignas de mención algunos trabajos que exhiben influencia de la teoría de la dependencia. En particular, se destaca el aporte de Francisco Suárez, titular de Sociología de la Organización y doctorado en Indiana University, en diversas obras en colaboración (Gallart, Ortega y Suárez, 1976, Suárez y Felcman, 1976), y la investigación de Bernardo Kliskberg (1973) sobre estrangulamiento tecnológico. La autogestión era un tema que podría haber resultado atractivo para los académicos de la época, dado el clima político y social, pero no hubo muchos estudios sobre la materia, salvo la 
obra Redistribución del poder y participación en las empresas: demandas para la reforma de la empresa de Roberto Martínez Nogueira (1975), docente de la FCE y doctorado en Cornell University.

La marea política cambió en 1976 y las expresiones de pensamiento radical, así como los intelectuales que las sostenían, pasaron a ser objeto de marcada hostilidad. Los profesores sospechados de simpatizar con posiciones de izquierda fueron cesanteados en sus cargos por los funcionarios designados como interventores de las diversas universidades públicas. La FCE de la UBA no fue una excepción. Del mismo modo, muchos que tuvieron que alejarse por presiones durante el régimen peronista fueron invitados a regresar a sus cargos.

El llamado proceso de reorganización nacional llevó adelante una auténtica desinstitucionalización de las ciencias sociales en Argentina, pero para la FCE de la UBA fue un mero regreso a la normalidad. La producción bibliográfica del período 1976-1982 siguió la línea de la edición exclusiva de libros de texto, reproduciendo la teoría administrativa americana. Como obras más destacables de dicho período, podemos mencionar Ciencia de la Administración de Jorge Hermida (1980) que constituye una interesante síntesis de las principales corrientes de pensamiento administrativo, culminando con una vindicación de la teoría de sistemas como enfoque más apropiado para estudiar a las empresas y operar sobre ellas.

Entre las voces que, en aquellos años, llevaron adelante una línea de pensamiento más original encontramos la de Oscar Oszlak, doctorado en ciencia política en la Universidad de Berkeley y especialista en administración pública. Oszlak, quien como la mayoría de los docentes en administración argentinos también se desempeñó como consultor, desarrolló su labor académica primero en el Instituto Di Tella y luego en el CEDES, del cual fue socio fundador. Si bien sus principales obras están dedicadas al estudio del Estado y las políticas públicas, realizó algunos aportes originales a la administración al analizar cómo los regímenes políticos afectan la estructura y las manifestaciones del comportamiento organizacional en la administración pública (Oszlak, 1980). Dicho trabajo relativiza la validez de las prescripciones "seudo-universales" de las teorías administrativas originadas en los países centrales, argumentando que algunos de los parámetros de funcionamiento de las burocracias latinoamericanas, aparentemente ineficientes y perversos desde la óptica de dichas teorías, se revelan como mecanismos alternativos para mantener un adecuado nivel de funcionamiento organizacional en el contexto de regímenes políticos muy distintos a los que rigen en los países donde se originan las perspectivas gerenciales dominantes. Una crítica más detallada a las teorías administrativas americanas se encuentra en Oszlak (1977).

El retorno a la democracia no generó ningún cambio en materia de creación y difusión de conocimiento administrativo, cuya dinámica ha sido casi independiente de elementos políticos, aunque sí marcó un momento de renacimiento de las ciencias sociales en el país (por ejemplo, en 1988 se creó la Facultad de Ciencias Sociales de la UBA). En materia de pensamiento administrativo, lo más destacable de mediados de los años ochenta fue el impacto de la administración estratégica. El principal referente de dicha problemática en el país era Jorge Hermida y, luego de su muerte, lo sería Roberto Serra, uno de sus más estrechos colaboradores. También Alberto Levy $(1981,1985)$ publicó obras de difusión de administración estratégica destinadas a empresarios, estudiantes y profesionales. En la segunda mitad de esta década, comenzó a cobrar importancia la literatura de "pop management" en Argentina y la difusión del pensamiento administrativo se independizó del libro de texto universitario, aunque muchas de estas obras populares tienen también a los estudiantes como destinatarios y sus autores son tanto profesores como consultores.

En esos años adquirió relevancia el nombre de Jorge Etkin, profesor de Dirección General en la FCE de la UBA, que llevó a cabo una labor académica de notable originalidad. Dentro de la teoría de los sistemas, de amplia trascendencia en el pensamiento administrativo argentino, introdujo nociones de la llamada "segunda cibernética", adaptando los desarrollos de Humberto Maturana y Francisco Varela, así como de otros pensadores constructivistas, al estudio de las organizaciones en Identidad organizacional: invariancia y cambio, obra escrita en colaboración con Leonardo Schvarstein (Etkin y Schavarstein. 1989). A ese libro, de amplio impacto, siguieron otros, todos marcados por un sello de originalidad y por la escasa dependencia del autor de las líneas de pensamiento dominantes en países centrales. De sus obras posteriores, entre las cuales cabe mencionar trabajos sobre la hipocresía en las organizaciones (Etkin, 1993) y la política organizacional 
(Etkin, 2000), sólo Gestión de la complejidad en las organizaciones (Etkin, 2003) tiene la estructura de un "manual de administración", pero incluso dentro de esta categoría exhibe en enfoque y contenido cierta distancia respecto a los manuales escritos por académicos americanos.

A principios de los noventa, se produjo una transformación central en la educación superior en administración de la República Argentina. Hasta fines de los ochenta, la producción de conocimiento local, que en gran medida consistía en la difusión y adaptación de conocimiento generado en Estados Unidos, tenía su locus principal en la FCE de la UBA, y la educación superior giraba en torno de las carreras de grado. Es cierto que diversas universidades públicas y privadas contaban con doctorados en ciencias económicas y ciencias administrativas, pero dichas carreras superiores no tenían muchos matriculados y estaban más orientadas a lo académico que al quehacer profesional. Por otra parte, existía un mercado de educación ejecutiva, atendido principalmente por instituciones terciarias no universitarias, que ofrecían cursos cuyos contenidos sí respondían a las necesidades de capacitación de las empresas. El segmento más exclusivo de dicho mercado estaba representado por el Instituto de Altos Estudios (IAE), fundado en 1978 y con estrechos vínculos con el IESE de España, e IDEA (Instituto para el Desarrollo de Ejecutivos en Argentina), una fundación sin fines de lucro apoyada por muchas de las principales empresas del país. En este contexto, el dictado de posgrados de nivel de maestría era un vacío a llenar, algo que no sólo afectaba a la educación en negocios sino a todas las disciplinas académicas en general. Esto es precisamente lo que cambió con una explosión en la oferta de posgrados en los años noventa (Barsky, 1997).

Durante dicha década, particularmente luego de la implementación del Plan de Convertibilidad en 1991, se vivió un clima de euforia empresaria. Con inflación cero, altas tasas de crecimiento, y el gobierno de un presidente peronista que parecía abrazar la fe en el libre mercado con la pasión de un converso convencido, se abrieron oportunidades de negocios en muchos campos. Numerosas empresas extranjeras se instalaron en Argentina en forma directa o a través de la adquisición de participación accionaria en empresas locales privadas o en proceso de privatización. A ello hay que añadir la inflación credencialista causada por la creencia de que la carrera de grado era insuficiente para asegurar un empleo en un mercado laboral altamente competitivo. ${ }^{6}$ Así, resulta comprensible que las universidades percibiesen la oportunidad de rédito económico representada por los posgrados de negocios, lo cual explica el surgimiento de cursos de especialización, programas de educación ejecutiva y maestrías en materia de administración, recursos humanos, negocios internacionales, marketing, finanzas, agronegocios, etc. Cabe señalar que, de la mano de esta expansión, se produjo también una internacionalización de las titulaciones, ya que muchas universidades se asociaron con instituciones extranjeras para ofrecer títulos conjuntos. ${ }^{7}$

Este boom de postgrados motivó la ampliación del plantel docente de universidades y escuelas de negocios. Si bien la mayoría de los docentes que integran los planteles de las instituciones de educación superior siguen desarrollando ocupaciones ejecutivas o de consultoría en forma paralela, se abrieron algunas posiciones fulltime. ${ }^{8}$ En particular, esto se verificó en las escuelas de negocios de elite, en su mayoría asociadas a universidades fundadas en los años noventa. En este sentido, es importante mencionar al IAE, con un número importante de profesores de dedicación exclusivazos, y a la Universidad de San Andrés.

Esta oportunidad de expansión de la educación superior en negocios se asoció a un boom editorial en materia de obras de management, que alcanzaron en los noventa niveles record de venta (Campanario, 2004). Entre las obras más destacadas dirigidas fundamentalmente a un público empresario, podemos mencionar a título meramente ejemplificativo los trabajos de Carlos Altschul (1993) sobre negociación, el de Serra (2000) sobre administración en el nuevo contexto económico, algunas obras de Rodolfo Biasca (1997), Guillermo Bilancio (2001) y Alberto Levy (1996). En general, se han publicado libros que constituyen obras de difusión, a veces matizadas con adaptaciones al contexto nacional, de enfoques y temas propios del nuevo paradigma del management de los noventa: organizaciones en red (Serra y Kastika, 1996), búsqueda de la calidad total (Perel, 1993), estructuras flexibles, empowerment de los recursos humanos, etc. Algunas obras publicadas en dichos años tienen un nivel académico destacable, tales como las de Jorge Etkin, los trabajos de Ernesto Gore (1996, 2003) sobre aprendizaje organizacional, el de Carlos Altschul (2003) acerca del rol del consultor, el de Enrique Herrscher (2003), Pensamiento Sistémico, y la última obra de Frischknecht (1993), Dirección Recursiva, por 
citar los más importantes. Sin embargo, el grueso de la producción bibliográfica entraría dentro de la categoría de literatura popular de management.

En materia de investigaciones empíricas elaboradas de acuerdo a los estándares propios de las publicaciones internacionales con referato no hubo un boom similar. Sin embargo, algunos autores argentinos, que desarrollaron estudios de posgrado en el exterior en la última década, pudieron ubicar sus trabajos en journals extranjeros. Entre ellos, podemos mencionar a Héctor Rocha y a Andrés Hatum, ambos del IAE (Rocha y Goshal, 2006; Hatum y Pettigrew, 2004). Esto sugiere que, debido a sus mayores recursos económicos, algunas universidades privadas lograron desafiar el monopolio hegemónico de la UBA en la creación de conocimiento administrativo. En tal sentido, es importante destacar a un grupo de instituciones llamadas "de élite", como las ya citadas IAE y San Andrés, a las que debemos añadir la Universidad Di Tella, creada sobre la base del prestigioso instituto del mismo nombre, y la Universidad del CEMA, originalmente un think tank de investigaciones económicas fundado por postgraduados de la Universidad de Chicago, muchos de cuyos docentes formaron parte del equipo económico que rigió la economía argentina durante el segundo gobierno del Presidente Menem.

En definitiva, puede afirmarse que el boom que la literatura pop de management experimentó en el plano internacional en los años noventa tuvo su correlato en la Argentina, donde alcanzaron niveles record de venta las obras de los gurús internacionales (Drucker, Peters, Senge, etc.) y, en menor medida, las de los autores locales. La realización de investigación académica sigue siendo una asignatura pendiente en el país, pese a algunas excepciones que parecen confirmar la regla. En rigor, no parece haber incentivos para que los docentes capacitados dediquen su tiempo a investigar y publicar en revistas con referato. Les resulta mucho más rentable actuar en consultoría, escribir best-sellers (que a su vez incrementan su visibilidad y prestigio como consultores) y desarrollar tareas de formación ejecutiva. Por otra parte, debe destacarse que pocas universidades y escuelas de negocios se preocupan por favorecer la investigación, ya que la cercanía de sus docentes al mundo empresario a través de su actuación como gerentes y consultores parece brindar a dichas instituciones mayor legitimidad (Álvarez et. al., 1997). En un país donde la administración se asocia ineludiblemente a la práctica, es una creencia generalizada que sólo aquellos que han alcanzado cierto nivel de éxito en el ámbito de la conducción de organizaciones, en sus múltiples aspectos, están capacitados para enseñar cómo lograr dicho éxito.

En esta última etapa de la evolución del conocimiento administrativo en Argentina resulta también evidente una tendencia a importar y reproducir las visiones dominantes en materia de management en los Estados Unidos. La producción enfocada al lado más académico de los estudios de administración no alcanza el nivel de los países desarrollados, en parte debido a la falta de una estructura de incentivos apropiada en universidades públicas y privadas, aunque se advierten algunos progresos o al menos la intención de abordar seriamente el tema. Existen razones económicas (una favorable relación costo-beneficio) para reproducir la faceta pop del conocimiento administrativo, pero no ocurre lo mismo con la faceta más académica de la disciplina, que es precisamente la base sobre la cual se construyen las reputaciones tanto de los profesores como de las escuelas de negocio en el Primer Mundo.

En síntesis, podemos concluir que la globalización académica ha tenido efectos en términos de: 1) programas de estudio (clonación de programas MBA, basados en el modelo americano), 2) replicación del paradigma de management dominante, 3 ) boom de la literatura de management pop. Al presente, es mínima la producción y difusión de conocimiento académico. No obstante, las presiones para que las escuelas de negocios locales generen auténtico conocimiento académico, más allá de la posibilidad de su aplicación concreta, probablemente se sentirán más en los años próximos, si es que dichas instituciones desean realmente alcanzar el nivel de sus pares de mayor prestigio en países desarrollados. ${ }^{9}$ 


\section{El caso español: una comparación pertinente con la configuración del conocimiento administrativo en Argentina.}

Evidentemente, el desarrollo del conocimiento administrativo en España ha estado profundamente influido por el contexto histórico, económico y social de un país que, como en el caso argentino, ha estado expuesto a períodos de turbulencia y dictaduras militares. La gestión empresarial contaba, a principios del siglo XX con pocas posibilidades de desarrollar teorías sólidas en una nación muy atrasada industrialmente, en la que la actividad se concentraba en sólo algunas regiones como País Vasco o Cataluña, en sectores como el textil y la siderurgia. España había pasado de ser el gran imperio mundial en el siglo XVI a un país atrasado en la semiperiferia europea, con anquilosadas estructuras económicas y políticas y una economía basada en la producción del sector primario. En general, las innovaciones dentro de la industria española fueron muy escasas e importadas desde el extranjero.

El Siglo XIX, marcado por las guerras carlistas y la inestabilidad política, asiste a un lentísimo y desigual despegue de la industria española, especialmente a partir de la Restauración monárquica de 1874. Los reinados de Alfonso XII y Alfonso XII y la regencia de la reina María Cristina (período 1874-1931) se caracterizan por el desarrollo económico en ciertas zonas, particularmente el norte y Cataluña donde se consolida paulatinamente una burguesía urbana y por supuesto un proletariado industrial. A la vez, el campo permanece anclado en métodos de cultivo anacrónicos y en estructuras sociales casi medievales, especialmente en el latifundista sur peninsular. Hasta los años veinte en que la dictadura militar de Primo de Rivera procede a implantar un programa de obras públicas y reorganización administrativa, apenas existe espacio alguno para el desarrollo de un pensamiento de carácter administrativo, salvo algunos antiguos esfuerzos de la época de la Ilustración (por ejemplo, la obra de Campomanes). De este modo, apenas existe producción editorial nacional de gestión empresarial hasta que el país se desarrolla económicamente a partir de la década de los sesenta del siglo XX. Al mismo tiempo, son pocas las páginas destinadas a investigar las aportaciones de los autores españoles en teoría de las organizaciones y el pensamiento administrativo. Los citados en la obra de José Luis García Ruiz Grandes creadores en la historia del management (2003) son quizá los más destacados, si bien ninguno de ellos sería probablemente reconocido entre los directivos españoles como una influencia clave en el desarrollo de los procesos de gestión de las empresas españolas. Ha tenido más importancia en el desarrollo del conocimiento administrativo el esfuerzo llevado a cabo por una serie de instituciones públicas y privadas a las que aquí se harán referencia.

No obstante, la lenta industrialización, aunque desigual, no fue inmune a las nuevas técnicas de producción. Hasta la Guerra Civil, desatada en 1936, los trabajos de autores españoles se centraron, fundamentalmente, en adaptar a la incipiente industria nacional las teorías de la Organización Científica del Trabajo de Frederick W. Taylor. En este sentido, destacaría la figura de César Madariaga, uno de los primeros importadores del sistema de producción en serie durante los años veinte y la II República, con obras como Organización científica del trabajo (1929), que sigue con escasas variaciones el discurso taylorista. Un acontecimiento de gran relevancia es la creación, en 1916, de la Universidad Comercial de Deusto, la primera escuela comercial española dirigida a gestores de empresas, promovida por la Compañía de Jesús. Como se señaló anteriormente, el País Vasco había conocido una fuerte industrialización, apoyada con capital extranjero y que descansaba en la explotación de las minas de Vizcaya y del resto de la Cordillera Cantábrica. El florecimiento de diversos entes económicos (bancos, compañías de seguros, astilleros, barcos) llevó a la necesidad de crear una institución dirigida a formar a los directivos de esos nuevos negocios (Revuelta, 1992). De esta institución, cuyo primer director es el sacerdote Luis Chalbaud, no sólo nacerá la primera Asociación de Licenciados en Ciencias Económicas de España, sino la prestigiosa revista Boletín de Estudios Económicos, publicada desde 1941 (Gómez-Benares y Revuelta, 2002). No obstante, pese al apoyo de personalidades como Giner de los Ríos, Unamuno u Ortega y Gasset, no prospera el proyecto de crear una facultad destinada al estudio de la economía en el sistema universitario público.

Los años treinta fueron en España políticamente muy turbulentos. La polarización ideológica durante la II República, fruto de las crecientes tensiones de clase en España (una derecha profundamente reaccionaria y opuesta a todo cambio social y económico en la atrasada nación; una izquierda revolucionaria organizada en 
torno a sindicatos de ideología socialista y, mayoritariamente, anarquista) termina en una insurrección militar que, fracasada en su intento de dar un golpe de estado, desemboca en un conflicto civil trágico que, tras tres años de guerra, lleva a la victoria militar del bando nacional liderado por el general Franco, de ideología nacionalista y apoyada por los fascismos europeos. En la postguerra se consolida un régimen, el franquista, que con la bandera de la autarquía como nueva organización económica, supuso una serie de cambios en la legislación laboral y la organización del trabajo industrial. El Fuero del Trabajo de 1938 favorece la creación de un sindicalismo vertical que alinea a trabajadores y empresarios en un esfuerzo común. Es de gran importancia asimismo la influencia de la ideología nacional-católica, vertebradora del régimen. Los años cuarenta se caracterizan por una intervención económica por parte del Estado en la fijación tanto de tipos de interés como de niveles de precios, y en el cierre de las fronteras a las mercancías, servicios y capital extranjero. Se crea el Instituto Nacional de Industria (INI) como eje de la modernización económica, y se consolida una burguesía con fuertes conexiones con el aparato administrativo-militar del Estado.

La autarquía como modelo de desarrollo interior, alentada por los falangistas nacional-católicos, fracasa estrepitosamente ante el creciente aumento del mercado negro y la incapacidad del INI de liderar dicha modernización. Ello lleva a la necesidad de reflexionar sobre la gestión, en un primer momento desde una perspectiva con fuerte influencia católica. De este modo, la reorganización de la industria es inspirada por una filosofía de gestión que combina por una parte los métodos de cadena de montaje con una idea de integración en la empresa propia de un corporativismo inspirado en la comunidad cristiana: un ejemplo es una obra como La cristianización de las empresas, del sacerdote jesuita Martín Brugarola (1945), en el que se exalta la comunión entre los miembros de la empresa y se critican los vicios del capitalismo. Junto a este trabajo, desde una perspectiva puramente taylorista, destacaría la obra de José Mallart Cutó con su Organización científica del trabajo (1956), el ministro franquista Pedro Gual Villalbí con su Política de la producción (1948) o la influencia de Fermín de la Serna, uno de los fundadores de la Escuela de Organización Industrial, la primera escuela de negocios de España, fundada en 1955 y dependiente del Ministerio de Industria. No obstante, el crecimiento industrial durante los años de la autarquía es muy escaso y hasta el Plan de Estabilización de 1959, con la liberalización de la economía, no se puede hablar del desarrollo de una sociedad de consumo incipiente que permita verdaderamente la consolidación de una producción en serie. Es de destacar, sin embago, que durante ese período se crea la primera Facultad de Ciencias Políticas y Económicas en la entonces conocida como Universidad Central de Madrid (hoy Complutense), que gozó de un inmediato éxito (Cuervo, 2002). Profesores importantes de esa primera época fueron economistas como Valentín Andrés Álvarez, José Castañeda y Manuel de Torres, además del breve pero importante paso del famoso economista alemán Heinrich von Stackelberg. Una década después se crea la misma Facultad en las universidades de Barcelona y del País Vasco.

El Plan de Estabilización Económica de 1959 supone la liberalización de los mercados productivos y la apertura a los capitales extranjeros, como consecuencia de un proceso de reconocimiento, por parte del bloque occidental, del régimen franquista tras años de aislamiento internacional. Desde los años sesenta, los planes de desarrollo inspirados por los gobiernos tecnócratas del Opus Dei, junto al crecimiento de las inversiones extranjeras y el turismo favorecen elevadas tasas de crecimiento económico y el desarrollo de patrones de consumo modernos (Nadal et al, 1987, Tortella, 1994). El país se transforma, pese a que continúa la represión política, y el desarrollo y las oportunidades estimulan el interés por la economía, la empresa y los estudios comerciales. Pronto se introducen las asignaturas de economía en las licenciaturas y se crean las primeras escuelas de negocios, lo que tuvo relación directa con las expectativas generadas por la apertura económica. Durante la década de los sesenta, se introducen los estudios de ciencias políticas y económicas en las universidades de Málaga, Valencia, Santiago de Compostela, y las Autónomas de Madrid y Barcelona. En 1971, se produce un cambio en los planes de estudios que separa finalmente las ciencias políticas de la economía, creándose las licenciaturas de Ciencias Políticas y Sociología y las de Económicas y Empresariales.

Durante este período se crean la mayor parte de las principales escuelas de negocios españolas. En 1955 el Ministerio de Industria crea la Escuela de Organización Industrial (EOI), cuyo primer director es Fermín de la Sierra y cuyo primer curso se celebra en 1957. Su objetivo es el de introducir estudios más sistemáticos sobre organizaciones y elevar la productividad de la muy ineficiente economía española de los cincuenta, formando a 
los funcionarios del INI. Contaba con el respaldo norteamericano en forma de apoyo técnico: el profesorado de la escuela se formaría en Estados Unidos (UCLA, Carnegie) y se contaría con invitados de dichas universidades. El enfoque es práctico, con grupos reducidos de alumnos y una importante interacción entre alumnos y profesores (Muñoz, 2005). La escuela con el devenir del tiempo se alejaría de la formación de funcionarios del Estado (particularmente ingenieros con vocación de gestión) para expandirse desde los ochenta al terreno de los máster en administración de empresas.

En el ámbito privado, se crean en el período 1958-1960 tres escuelas de negocios muy importantes: IESE, ESADE e ICADE, todas ellas caracterizadas por el carácter religioso de sus impulsores. El IESE (Instituto de Estudios Superiores de la Empresa) surge como una iniciativa del sacerdote y fundador del Opus Dei José María Escrivá de Balaguer, que deseaba crear en Barcelona una institución para formación de directivos que combinase los más modernos conocimientos en organización con una sólida formación cristiana (Argandoña, 2002). Para ello, a primeros de los años sesenta adoptó la metodología del caso a partir de sus colaboraciones con la Harvard Business School, poniendo en marcha el primer MBA en 1964. ESADE (Escuela Superior de Administración y Dirección de Empresas) nace del interés por parte del empresariado catalán por contar con un centro similar a Deusto en Cataluña, por lo que encarga a la Compañía de Jesús la dirección de una nueva escuela, cuyo primer curso se imparte en Barcelona en 1959. Su modelo es el de la escuela de negocios norteamericana, aunque también trata de servir de foro para empresarios (Güiell, 2002). Finalmente, ICADE (Instituto Católico de Administración y Dirección de Empresas) es la Facultad de Ciencias Económicas y Empresariales de la Universidad Pontificia de Comillas (Madrid), dirigida también por la Compañía de Jesús. Su primer curso comenzó en 1960. Todas ellas mantienen en la actualidad un enorme prestigio y se caracterizan, desde sus orígenes, por su enfoque managerial en el estudio de la administración de empresas (Martínez Laquidain, 2002)).

Paralelamente a este desarrollo del conocimiento administrativo, se importan algunas modas de gestión norteamericanas. Tras la importación del taylorismo, el siguiente foco de interés es la Escuela de las Relaciones Humanas, cuyo principal representante es Elton Mayo. Aquí tiene especial interés la doctrina social cristiana, con representantes como Martín Brugarola en una época posterior a la antes citada ${ }^{10}$. Pero, por supuesto, la clave del management español de los años sesenta es la introducción de técnicas de gestión cercanas a la psicología industrial. La influencia tanto del Mayoísmo como de la Escuela de Neorrelaciones Humanas es muy notable en España, quizá por su encaje con la filosofía corporativista del franquismo. Roberto Cuñat (que posteriormente también será uno de los importadores del management por objetivos) y Miquel Siguan con su Problemas humanos del trabajo industrial (1959) son algunos de sus principales representantes. José Mallart (anteriormente taylorista) se centra posteriormente también en estos modelos de la psicología industrial. Ramón de Lucas Ortueta se consolidará como uno de los principales representantes de la teoría de los Recursos Humanos, con su Manual de Personal. Técnicas de dirección de empresas (1987). Paralelamente, en las Universidades se empieza a consolidar la asignatura de economía de la empresa, con representantes como García Echevarría, López Moreno y, sobre todo, José María Fernández Pirla con su obra clásica Economía y gestión de la empresa (1981), labor continuada por profesores universitarios como Eduardo Bueno o Ignacio Cruz Roche.

La figura del empresario, por otro lado, es exaltada por diversos expertos. Así, el sacerdote Mariano Sánchez Gil, que en su Naturaleza y evolución de la función empresarial (1969) es uno de los primeros autores en defender una autoridad horizontal. Otros autores destacados son Ramón Arana, que en su obra El trabajo personal del director de empresa (1963) trata la importancia de los directivos en las empresas y sus funciones, o Gabriel Barceló que describe en El dirigente del futuro (1972) unas cualidades de los mismos muy alejadas del clásico patrón; la innovación será defendida por Bernardino Herrero, que se centra en la figura del emprendedor siguiendo al Drucker de los años setenta.

El final del franquismo se caracteriza por los tremendos efectos de la crisis del petróleo en la economía española, que lleva a una reestructuración del capitalismo español durante las siguientes décadas (Etxezarreta, 1991). Durante la transición democrática se gestan los Pactos de la Moncloa, por los que la economía española se mantiene como una economía de libre mercado y se adquiere una cierta estabilidad en el modelo. Desde los 
años ochenta, se va consolidando progresivamente el interés por la gestión empresarial, fundamentalmente por dos factores: la reconversión industrial, por un lado, y la progresiva desregulación de la economía fruto de su incorporación a la Comunidad Económica Europea. Las políticas económicas de ajuste y un clima de construcción de confianza empresarial llevan a un desarrollo del management en su vertiente editorial. Autores destacados en los años ochenta son Pedro Uriarte con su enfoque psicosociológico y Gabriel Barceló con su obra La formación del dirigente, en la que en quince puntos detalla la misión de los directivos. Comienzan a publicarse obras en todas las variantes y subgéneros del management, amén de colecciones de clásicos de pensamiento empresarial como las editadas por Folio, Orbis o Grijalbo. La Universidad de Deusto y el IESE (escuela de administración de empresas vinculada a la Universidad de Navarra) realizan investigaciones en cuestiones de gestión. Pronto la enseñanza en económicas y empresariales se extiende por las universidades de todo el país (particularmente, desde la división entre licenciatura en ciencias económicas y licenciatura en ciencias empresariales en 1990, división todavía existente aunque con otros nombres: ahora son economía y administración de empresas). No obstante, y a nivel de postgrado, el prestigio lo retendrán las escuelas de negocios antes citadas y el Instituto de Empresa, creado a iniciativa de empresarios madrileños a principios de la década de los setenta y que destaca por su carácter aconfesional. En los últimos años, se ha convertido en una de las escuelas de negocios más prestigiosas de Europa.

En España, la democracia (con su libertad de expresión) y el desarrollo industrial y económico son recientes, y ello ha influido en una configuración de la enseñanza de las ciencias empresariales muy particular. Durante décadas la teoría de la organización impartida excluía de manera deliberada el marxismo de sus programas académicos. El análisis de la acción del trabajador, sus aspiraciones, el desafío de su integración y otros factores sociales quedaba restringido a lo que se puede decir y a lo que se puede estudiar dentro de un contexto autoritario que, además, había aislado a su comunidad universitaria de los principales debates teóricos. Otro problema ha sido la dependencia de la economía como vertebración de los contenidos docentes. Como señala Cuervo (2002), en España los estudios de administración de empresas en las facultades de las universidades públicas se consideraron, generalmente, como una simple continuación de la disciplina de la economía de empresa, y no existió con la economía una ruptura en la metodología o en los contenidos: así, la teoría económica de la empresa con su dogmatismo teórico es todavía hegemónica en los planes de estudios, frente a la teoría y la psico-sociología de las organizaciones. Según Cuervo (2002), los defectuosos planes de estudios, mal adaptados a las exigencias del mercado, y la desconfianza de las universidades hacia los estudios de postgrado tipo master terminan por dejar un sector importante de los estudios de mayor nivel (postgrado, como es el caso del master) en manos de otras instituciones académicas. Así, las escuelas de negocios en España han acaparado este espacio, y han sido creadas, casi en su totalidad, por la iniciativa privada. En el caso de España, el conocimiento que se ha impartido en las universidades se ha organizado en torno a las disciplinas de conocimiento, y la docencia se ha impartido en planes de estudio oficiales y sancionados legalmente por el Boletín Oficial del Estado. Esto lleva a una cierta rigidez que sólo puede superarse a través de los seminarios de doctorado o los masters, lugares en los que pueden redefinirse los cursos con mayor facilidad.

España, en las últimas décadas, se ha convertido finalmente en una economía plenamente capitalista (y postfordista), teniendo algunas de sus grandes empresas una dimensión claramente multinacional. El extraordinario éxito de corporaciones como el Grupo Inditex, con comercios en todo el mundo; la expansión de Telefónica o el Grupo Santander no solamente en los mercados latinoamericanos sino europeos (con adquisiciones tan sonadas como la empresa de móviles $\mathrm{O}^{2}$ o el Abbey National Bank, respectivamente); e intentos de consolidar empresas en el mundo tanto de la consultoría como de Internet con empresas como Meta 4 o Terra (no siempre con los resultados esperados) demuestran que España no es sólo, aunque a veces lo parezca, una economía centrada exclusivamente en la construcción y el turismo. Otras empresas exitosas españolas han sido adquiridas por multinacionales extranjeras (Airtel, Amena). Hay un tejido empresarial que, con sus deficiencias y cualidades, ha dado pasos hacia una mayor competitividad en los mercados internacionales, con una especialmente fuerte interrelación con Europa. España es así una economía de servicios en la que no sólo se evoluciona hacia una economía informacional, sino que, en materias de gestión, se han seguido los modelos norteamericanos (base además de la formación impartida en las escuelas de negocios). 
Las escuelas de negocios españolas, además de ser instituciones privadas, cuentan con una peculiaridad: salvo el Instituto de Empresa y la EOI, las escuelas de administración de empresas más conocidas y prestigiosas han tenido vínculos muy estrechos con la Iglesia Católica. La Compañía de Jesús ha creado por ejemplo la Universidad Comercial de Deusto (la primera escuela de comercio española, nada menos que en 1919), ESADE (Escuela Superior de Administración y Dirección de Empresas) o ICADE (Instituto Católico de Dirección de Empresas); el Opus Dei, IESE (Instituto de Estudios Superiores de la Empresa). La mayor parte de ellas fueron creadas durante el desarrollismo, con el fin de formar a los directivos de la futura sociedad española. En la actualidad, su prestigio internacional es enorme, y atraen a participantes con ambiciones muy concretas en el mercado laboral. En los programas de estudio de dichos masters los cuestionamientos del marco en el que se desenvuelve la actividad empresarial no son abundantes, siendo el directivo el depositario de la racionalidad dentro de la empresa. Se estudian asignaturas como liderazgo, gestión de recursos humanos, estrategia empresarial, marketing, comercio internacional o ética y, aunque existen por supuestos excepciones (por ejemplo, Luis de Sebastián), el tono general es cercano a los estudios empresariales típicos, no críticos. Predomina la metodología de caso sobre aproximaciones cercanas a los estudios culturales, y si éstos se dan, se enfocan alejados de la teoría crítica. Además, los referentes teóricos son, en general, autores cercanos a lo que se podría definir como perspectivas convencionales de la gestión empresarial (Kotler, Porter), cuando no se alude directamente a los últimos best-sellers de los gurús del management (Goleman, Hammer y Champy y similares). En España existe un proyecto académico de corte managerialista y pro-empresarial más o menos delineado, fuertemente vinculado a las relaciones entre escuelas de negocios (donde una parte muy importante de su personal ejerce, además de actividad docente, actividad profesional en el mercado, normalmente en el sector de la consultoría) y empresas. Las nuevas universidades privadas de los noventa (CES, Alfonso X El Sabio, etc.) y las nuevas escuelas de negocios (IADE, etc.) se han adherido a estos enfoques.

A finales de los noventa el número de publicaciones comienza a aumentar y se consolida una nómina de autores equivalentes a los gurús del management mundiales a escala española. La recuperación de la economía, junto a unos valores pro-empresariales dominantes en política, favorece el crecimiento del campo del management, que se adapta a las características del campo managerial estadounidense. Surgen además editoriales como Urano con su colección Empresa Activa, que se unen a otras especializadas como Gestión 2000, Ariel (colección Empresa), Prentice Hall, Pearson Educación o Deusto. Como en el caso estadounidense, en los últimos años no ha existido una moda de gestión que pueda ser considerada dominante, sino que varias compiten entre sí por hacerse con el mayor hueco en el mercado. En general, el paradigma de las redes es claramente dominante, reforzado por el desarrollo continuo de las nuevas tecnologías. Esto lleva a un énfasis en la adaptabilidad y la flexibilidad de empresas y trabajadores, y métodos de dirección fundamentados en aspectos normativos con pretensiones humanistas, tales como la Dirección por Valores (García Sánchez, 1997), que propugna que "la $\mathrm{DpV}$ es la dimensión organizativa de un Capitalismo Sensible impulsado por emprendedores con valores" (García Sánchez, en VVAA, 2002: 234) o la Gestión de la Confianza (Fernández López, 2002). De este modo, cuando José Aguilar habla de Gestión del Cambio, afirma que "también pueden ser dirigidas realidades que tienen cierto carácter de intangibles: por ejemplo, y de modo muy importante, la buena voluntad y disposición de las personas con las que se trabaja", siendo el concepto de agente del cambio equivalente al de líder en este enfoque (Aguilar, en VVAA, 2002: 39).

¿Qué autores del nuevo pop management se encuentran hoy en día entre las principales referencias en España? El libro de García Ruiz (2003) incluye un apéndice, redactado por Juan Carlos Cubeiro y dedicado a los principales expertos que, durante los últimos cinco años, tratan de configurar un grupo de gurús similares a los existentes en el Entrepreneurial Period de Estados Unidos, con procedencias de diferentes ámbitos: profesores de escuelas de administración de empresas, consultores de dirección y profesores universitarios. Del ámbito universitario, destaca a Eduardo Bueno (si bien su enfoque es más próximo a una teoría sistémica de la empresa más que al propio management), Salvador García Sánchez (el creador de la Dirección por Valores) y Guido Stein (de la Universidad de Navarra). Pero especialmente, sobresalen los autores que proceden del ámbito de la empresa privada y, dentro del mismo, aquellos provenientes de la consultoría empresarial, particularmente de la conocida empresa (hoy desaparecida) Arthur Andersen: de dicho entorno proceden Juan Carlos Cubeiro y su liberación del talento, adaptación de la filosofía de Tom Peters y reflejada en obras como TGP (1999); Santiago 
Álvarez de Mon, centrado en la gestión del compromiso, y Nuria Chinchilla, cuyos textos alaban a las mujeres emprendedoras y la necesidad de una "...selección de personal que tenga en cuenta también el perfil motivacional de los candidatos" (Chinchilla, en VVAA, 2002: 193); Javier Fernández López, defensor de una Gestión de la Confianza en la que plantea un modelo CLIC basado en la Confianza, Liderazgo, Integración y Conocimiento; José Manuel Casado, Pedro Nueno y Alfonso Jiménez. Otros autores son José Aguilar, que se centra en la gestión del cambio en la obra del mismo título (Aguilar, 2003); Javier Fernández Aguado, que ha definido el modelo teórico de gestión conocido como Gestión de lo Imperfecto; Pilar Jericó defiende la Gestión del Talento (Jericó, 2001); y Carlos Herreros su coaching ejecutivo. Este último se ha centrado en la actualidad en la narrativa empresarial, fenómeno de enorme crecimiento; le acompañan en esta tarea el ya citado Cubeiro, con obras exitosas como La sensación de fluidez (2001); Fernando Bayón, especialista en recursos humanos, bajo el seudónimo de Henry Bay, o José María Ortiz Ibarz (ver García Ruiz, 2003). Recientemente, uno de los mayores éxitos de ventas ha sido la fábula La buena suerte (Rovira y Trías de Bes, 2004). Existe además alguna autobiografía de directivo con cierto interés, como La rebelión de los directivos: ¿pasión o razón? (Amichis, 1998). Así, el pop management se consolida.

Por otra parte, también la faceta más académica del conocimiento administrativo ha sufrido un impulso en España en los últimos años. Esto probablemente obedezca a que las instituciones de educación superior españolas procuran incrementar su legitimación como tales a través de la imitación de las normas y prácticas de instituciones extranjeras consideradas como role models (en el caso que nos ocupa, las universidades de países anglosajones y, particularmente, de los Estados Unidos). ${ }^{11}$ Entre las prácticas y normas a las que nos referimos, es fundamental el "publish or perish", que indica que la suerte de un docente universitario se encuentra muy estrechamente vinculada a su contribución al conocimiento científico en su especialidad. En efecto, la introducción en 1990 de una política de incentivos para los investigadores en función de su productividad científica es, según de Moya-Anegón y Herrero (1999), el factor central que explica el incremento que se ha verificado a partir de entonces del número de publicaciones de académicos españoles en journals internacionales con referato. La disciplina de la administración no parece haber sido ajena a este fenómeno, ya que es posible encontrar colaboraciones de autores con afiliación a instituciones españolas en revistas científicas de primer nivel tales como Organization Studies, Organization, Organization Science, Journal of Management Studies, Academy of Management Journal, etc. Es interesante, no obstante, destacar que aunque la participación de académicos españoles en revistas internacionales de administración con arbitraje está creciendo, un análisis cientométrico reciente de la producción científica de dicho país en economía y administración revela que la mayor parte de las publicaciones corresponde a la primera de estas disciplinas (Suriñach et al., 2005). ${ }^{12}$

En resumen, el caso español ofrece una interesante similitud con el argentino, en tres cuestiones fundamentales. Por una parte, la situación periférica que ambos países comparten en la generación de conocimiento administrativo, fruto en buena medida de las posiciones que, históricamente, han tenido en el sistema capitalista mundial, más allá de momentos de euforia económica o depresión. En segundo lugar, y debido en parte a dicha cuestión, la influencia que en ambos casos ejerce el modelo anglosajón de teoría organizacional, importado a lo largo de las últimas décadas, y hegemónico en la enseñanza de administración de empresas. Y en tercer lugar, el peso que la rentabilización de los cursos de postgrado en el mercado laboral ejerce sobre los programas de estudios, lo que deja la investigación científica en manos de las universidades públicas que, en el caso de las ciencias sociales, no siempre están muy bien dotadas económicamente.

\section{Conclusión.}

La precedente reconstrucción de los principales desarrollos en materia de conocimiento administrativo en Argentina permite extraer varias conclusiones. En primer lugar, hay una regularidad muy importante: el carácter profesionalista de la orientación de la educación superior en negocios y, consecuentemente, del conocimiento que se genera y difunde en este contexto. 
Hasta la reforma curricular de 1958 en la UBA, la mayor parte de lo que entendemos por conocimiento general de administración se asocia a los manuales teóricos universitarios. La perspectiva dominante es la administración científica, aunque hay algunos desarrollos teóricos originales (Palacios, Gilli) que incluso desafían a los enfoques dominantes. En principio, esto no debe sorprender ya que en los años cincuenta incluso en países como Estados Unidos la enseñanza universitaria de la administración no gozaba de gran prestigio (Leavitt, 2005), pese a que se investigaba mucho más en temas organizacionales. Con posterioridad a 1958, se produce una progresiva actualización de los conocimientos administrativos que se enseñan en el país. La teoría de la organización y la escuela de sistemas ganan terreno como perspectivas dominantes, contando no sólo con autores que las difunden sino con algunos que generan sus propias perspectivas de pensamiento asociadas a las mismas. Pero conviene recordar que, siguiendo una invariancia central de la educación superior en administración, los principales referentes académicos en la disciplina son también consultores. En estrecha relación a ello, hay pocos trabajos auténticos de investigación empírica en la materia. En este sentido, las pautas coinciden con el desarrollo del conocimiento administrativo en España.

En la década del noventa, la educación en negocios atraviesa un boom: el auge de los posgrados en negocios. La literatura de management se transforma también en un éxito editorial. Esto no resulta muy diferente de lo que se vive en el resto del mundo. Pero siguiendo con el fuerte vínculo entre conocimiento administrativo y praxis profesional, la vertiente más sofisticada y rigurosa del conocimiento administrativo académico no recibe mayor atención. Este es un elemento de gran especificidad que caracteriza al caso argentino. Si bien debe señalarse que en los últimos años algunas universidades privadas de reciente creación han contratado docentes formados que realizan algunas tareas de investigación, probablemente por el hecho de que se ven obligadas a copiar pautas de funcionamiento propias de las escuelas de negocios del primer mundo, la baja significatividad de la investigación académica en administración es algo que hay que destacar en el panorama del conocimiento administrativo argentino. Lo poco que se hace en la materia sigue siendo el fruto de esfuerzos individuales, aislados y asistemáticos (Suárez et al., 2004; Góngora y Nóbile, 2006). En síntesis, la marcada orientación profesionalista del conocimiento administrativo y el escaso interés por la investigación son elementos que han contribuido a la escasa generación de conocimiento local y a la manifiesta vocación por importar lo generado en el extranjero.

En España, hay un grado mayor de producción académica en la disciplina. Ello se debe a que tanto escuelas de negocios como universidades públicas cuentan en dicho país con mayores recursos económicos que sus pares argentinas, lo cual es fruto del tardío pero exitoso camino de España hacia el desarrollo económico. Ineludiblemente, España debe alinear su nivel de generación de conocimiento científico con el de otros países de la comunidad económica de la cual es parte. Sin embargo, debe precisarse que incluso en dicho país, que goza actualmente de cierta prosperidad económica, el desarrollo de la faceta científica de la administración es opacado por el nivel de producción científica en disciplinas afines como la economía.

A modo de conclusión, se puede afirmar que existen importantes paralelismos entre los dos países. Particularmente, su posición de "importadores" de conocimiento administrativo y el hecho de que la orientación dominante de la disciplina sea marcadamente profesionalista, en detrimento de la generación del conocimiento original más riguroso, propio de la literatura organizacional y administrativa de índole científica. Queda como cuestión abierta, que sólo con el transcurso del tiempo podremos responder, verificar si España, en tanto nación que procura consolidar su posición de alto desarrollo económico, converge en sus patrones de generación de conocimiento administrativo con los países líderes en la materia como Estados Unidos, Canadá y el Reino Unido. Si España no lo consigue, es difícil pensar que Argentina lo logre antes. 


\section{Referencias}

Aguilar, J. (2003) Gestión del cambio. Barcelona: Ariel.

Altschul, C. (1993) Todos ganan. Buenos Aires: Paidós.

Altschul, C. (2003) Estar de paso: roles y competencia del consultor. Buenos Aires: Granica.

Alvarez, J. L. (ed.) (1998) The diffusion and consumption of business knowledge. New York: St. Martin's Press.

Amichis, R. (1998) La rebelión de los directivos: ¿pasión o razón, Biblioteca Nueva: Madrid.

Arana Gondra, R. (1963) El trabajo personal del director de empresa. Bilbao: Deusto.

Argandoña Rámiz, A. (2002) "El IESE: una escuela global de formación de directivos", en E. Fuentes Quintana (dir.), Economía y economistas españoles vol. 7: La consolidación académica de la economía. Barcelona: Galaxia Gutenberg / Círculo de Lectores.

Bagur, B., P. Pavesi y R. Pérez (1977) Decisión y planeamiento. Buenos Aires. El Coloquio.

Barceló, G. (1972) El dirigente del futuro. Madrid: Asociación para el Progreso de la Dirección.

Barsky, O. (1997) Los posgrados universitarios en la República Argentina. Buenos Aires: Troquel

Bialet-Massé, J. (1904) Informe sobre el estado de las clases obreras en el interior de la República. Buenos Aires: Grau.

Biasca, R. (1997) Renovación intencional. Buenos Aires: Macchi.

Bilancio, G. (2001) Antióxido. Buenos Aires: Prentice-Hall.

Brugarola, M. (1945) La cristianización de las empresas. Madrid: Fax.

Brugarola, M. (1971) Para ti, dirigente de empresa. Madrid: Asociación Eclesiástica Nacional de Sindicatos.

Camacho, H. H. (1971) Las ciencias naturales en la Universidad de Buenos Aires, Buenos Aires: Eudeba, citado en O. Barsky (1997), Los posgrados universitarios en la República Argentina. Buenos Aires: Troquel.

Cámara de Diputados de la República Argentina (1923) Intervención de empleados y obreros en la gestión de empresas y fábricas. Buenos Aires.

Campanario, S. (2004) Libros de negocios: la receta para cocinar un best seller. Clarín, Suplemento Económico, Mayo 23: 35.

Ciria, A. y H. Sanguinetti (1987) La Reforma Universitaria/1 (1918-1983). Buenos Aires: Centro Editor de América Latina.

Cubeiro, J. C. (2000) TGP (Tu gurú particular). Barcelona: Martínez Roca.

Cubeiro, J. C. (2001) La sensación de fluidez. Madrid: Prentice Hall.

Cuervo, A. (2002) "De la economía de la empresa a la administración de empresas. Reflexiones sobre los estudios de empresa en España", en E. Fuentes Quintana (dir.), Economía y economistas españoles vol. 7: La consolidación académica de la economía. Barcelona: Galaxia Gutenberg / Círculo de Lectores.

de Moya-Anegón, F. y V. Herrero-Solana (1999) "Science in America Latina: a comparison of bibliometric and scientifictechnical indicators", Scientometrics 46 (2): 299-320.

DiMaggio, P. y W. Powell (1983) "The iron cage revisited: Institutional isomorphism and collective rationality in organizational fields", American Sociological Review, 48: 147-60.

Escudero, G. C. (1942) La organización científica del trabajo, Buenos Aires: Jesymar.

Etkin, J. y L. Schvarstein (1989) Identidad de las organizaciones: Invaritancia y cambio. Buenos Aires: Paidós. 
Etkin, J. (1993) La doble moral de las organizaciones: Los sistemas perversos y la corrupción institucionalizada. Madrid: McGraw-Hill

Etkin, J. (2000) Política, gobierno y gerencia de las organizaciones; acuerdos, dualidades y divergencias. Buenos Aires: Prentice Hall.

Etkin, J. (2003) Gestión de la complejidad en las organizaciones: La estrategia frente a lo imprevisto y lo impensado. México: Oxford University Press

Etxezarreta, M. (ed.) (1991) La reestructuración del capitalismo en España, 1970-1990. Madrid: Icaria / FUHEM.

Felcman, I. y F. Suárez (1976) Tecnología y Organización. Buenos Aires: El Coloquio.

Fernández López, J. (2002) Gestionar la confianza. Madrid: Prentice Hall.

Fillol, T. (1961) Social Factors in Economic Development: The Argentine Case. Cambridge, The MIT Press.

Frischknecht, F. (1966) La gerencia y la empresa. Buenos Aies: El Ateneo.

Frischknecht, F. (1978) Organización. Buenos Aires: El Ateneo..

Frischknecht, F. (1993) Dirección recursiva de las ideas a la acción y de la acción a las ideas. Buenos Aires: El Ateneo.

Frischknecht, F. y Van Gigch, J. P. (1989) "The Information-System-Processing Triad: Common Core of Human Disciplines", Behavioral Science 34(4):239-252.

Gallart M. E., E. Ortega y F. Suárez (1976) La inserción de las organizaciones en los procesos sociales. Buenos Aires: El Coloquio.

García Pazos, M. y F. Frischknecht (1963) Manual de administración de empresas. Buenos Aires: Centro de Estudiantes de Ciencias Económicas de la Universidad de Buenos Aires.

García Ruiz, J. L. (2003) Grandes creadores en la historia del management, Barcelona: Ariel.

García Sánchez, S. (1997) La dirección por valores. Madrid: McGraw-Hill.

Gilli, J. A (1944) La fábrica: De Marx a Ford. Buenos Aires: Hachette.

Gómez-Benares, F. y D. Revuelta (2002) "La Universidad Comercial de Deusto: pionera de los estudios de economía en España", en E. Fuentes Quintana (dir.), Economía y economistas españoles vol. 7: La consolidación académica de la economía. Barcelona: Galaxia Gutenberg / Círculo de Lectores.

Góngora, N. y C. Nóbile (2007) ¿Qué se investiga en Administración? El caso argentino. Documento de Trabajo, Universidad de La Plata.

González Rojas, I. (1988) "La enseñanza de las Ciencias de la Administración en la República Argentina", Administración de Empresas 19 (3): 367-84.

Gore, E. (1996) Educación en las empresas: aprendiendo en contextos organizativos. Buenos Aires: Granica.

Gore, E. (2003) Conocimiento colectivo. Buenos Aires: Granica.

Groba, E. (1960) Employees behavior under an administrative reorganization process. Buenos Aires: mimeo.

Gual Villalbí, P. (1948) Política de la producción. Barcelona: Editorial Juventud.

Güell Fortuny, A. (2002) "ESADE: historia y razón de ser", en E. Fuentes Quintana (dir.), Economía y economistas españoles vol. 7: La consolidación académica de la economía. Barcelona: Galaxia Gutenberg / Círculo de Lectores.

Hatum, A.. y A. Pettigrew (2004), "Determinants of organizational flexibility: A study in an emerging economy", British Journal of Management, 17 (2), 115-137. 
Hermida, J. (1980) Ciencia de la Administración. Buenos Aires: Ed. Contabilidad Moderna.

Herrscher, E. (2003) Pensamiento Sistémico, Buenos Aires, Granica.

Hoyo, A. (1922) La organización científica del trabajo y la producción y el problema obrero. Buenos Aires: Rina.

Jericó, P. (2001) Gestión del talento. Madrid: Prentice Hall.

Kliksberg, B. (1973) Administración, subdesarrollo y estrangulación tecnológica: Introducción al caso latinoamericano. Buenos Aires: Paidós.

Kliskberg, B. (1971) El pensamiento administrativo. Buenos Aires: Depalma.

Leavitt, H. (2005) Top down: Why hierarchies are here to stay and how to manage them more effectively. Boston: Harvard Business School Press

Levy, A. (1981) Planeamiento estratégico. Buenos Aires: Macchi.

Levy, A. (1985) Estrategia en acción. Buenos Aires: Macchi.

Levy, A. (1996) Marketing avanzado; un enfoque sistémico y constructivista de lo estratégico y de lo táctico. Barcelona: Granica.

Levy, A. y A. Wilensky (1987) Cómo hacen los que hacen; claves empresariales para la Argentina compleja. Buenos Aires: Ed. Tesis.

Lewis, P. H. (1993) La crisis del capitalismo argentino. Buenos Aires: FCE:.

Lucas de Ortueta, R. (1987) Manual de personal. Técnicas de dirección de personal. Madrid: Index.

Llamazares, J. E. (1955) Empresas modernas: ensayos sobre dirección y organización. Buenos Aires: Instituto Argentino de Relaciones Industriales.

Madariaga Rojo, C. (1929) Organización científica del trabajo. I. Las ideas. Madrid: Juan Ortiz,.

Mallart Cutó, J. (1956) Organización científica del trabajo. Madrid: Labor.

Martínez Laquidain, J. (2002) "De ICADE a Comillas: historia de una facultad de ciencias económicas y empresariales", en E. Fuentes Quintana(dir.), Economía y economistas españoles vol. 7: La consolidación académica de la economía. Barcelona: Galaxia Gutenberg / Círculo de Lectores.

Martínez Nogueira, R. (1975) Redistribución del poder y participación en las empresas; demandas para la reforma de la empresa. Buenos Aires: El Coloquio.

Muñoz, P. (2005) EOI: cincuenta años en vanguardia, Madrid: EOI Escuela de Negocios.

Nadal, J., A. Carreras y C. Sudriá (eds.) (1987) La economía española en el siglo XX. Una perspectiva histórica. Barcelona: Ariel.

Ollier, M. M. (1998) La creencia y la pasión. Privado, público y político en la izquierda revolucionaria. Buenos Aires: Ariel.

Oszlak, O. (1977) Notas críticas para una teoría de la burocracia estatal. Documentos CEDES No 8, Buenos Aires.

Oszlak, O. (1980) Políticas públicas y regímenes políticos. Estudios CEDES, vol. 3, No 2, Buenos Aires.

Palacios, A. (1922) La fatiga y sus proyecciones sociales. Buenos Aires: Rosso.

Pavesi, P. (1963) Introducción a la teoría de los fenómenos de espera. Buenos Aires: Facultad de Cs. Económicas.

Perel, V. L. (1961) Manual de administración y racionalización de empresas. Buenos Aires: Disa.

Perel, V. L. (1993) La organizaciones neuróticas: de la neurosis a la calidad total. Buenos Aires: Macchi.

Perel, V. L et al. (1980) La administración al alcance de casi todos. Buenos Aires: Macchi. 
Revuelta Sáez, M. D. (1992) La Universidad Comercial de Deusto: 75 años formando profesionales para la empresa. Bilbao: Fundación Luis Bernaola.

Rocha, H. y S. Ghoshal (2006) "Beyond Self-Interest-Revisited", Journal of Management Studies 43 (3): 585-619.

Rovira Celma, A. y F. Trias de Bes (2004) La buena suerte. Claves de la prosperidad, Barcelona: Urano.

Ruiz Soler, L. (1924) Elementos de administración y contabilidad de empresas, Irún: Arri.

Sacristán y Zabala, A. (1925) Teorías de contabilidad general y de administración privada. Madrid: Rivadeneyra.

Sahlin-Andersson, K. y L. Engwall (eds.) (2002) The expansion of management knowledge: Carriers, flows, and sources. Stanford, CA: Stanford University Press.

Sánchez Gil, M. (1969) Naturaleza y evolución de la función empresarial. Madrid: Aguilar.

Serra, R. (2000) El nuevo juego de los negocios. Buenos Aires: Norma.

Serra, R. y E. Kastika (1996) Re-estructurando empresas: Las nuevas estructuras de redes para diseñar las organizaciones del próximo siglo. Buenos Aires, Macchi.

Siguan, M. (1959) Problemas humanos del trabajo industrial. Madrid: Rialp.

Suárez, F., S. Agoff, M. Contreras, M. Losano y M. Zonis (2004) La construcción del saber administrativo en la Argentina: una aproximación operacional. Buenos Aires: Facultad de Cs. Económicas, Universidad de Buenos Aires.

Suriñach, J., J.C. Duque, R. Ramos y V. Royuela (2005) El impacto de las publicaciones científicas españolas en Economía y Empresa: Un análisis Bibliométrico, Documento de Trabajo, Univ. de Barcelona, http://www.mec.es/univ/proyectos2005/EA2005-0142.pdf, con acceso el 7/11/2007.

Tortella, G. (1994) El desarrollo de la España contemporánea. Historia económica de los siglos XIX y XX. Madrid: Alianza.

Üsdiken, B. (1997) "Importing theories of management and organization: The case of Turkish Academia", International Studies of Management and Organization 26: 33-46.

Üsdiken, B. (2004) "Exporting managerial knowledge to the outpost: Penetration of 'Human Relations' into Turkish Academia, 1950-1965", Management Learning. 35: 255-270.

V.V.A.A. (2002) Management español: los mejores textos. Barcelona: Ariel.

Wainer, J. (1943) Racionalización Administrativa. Buenos Aires, Editorial Argentina de Finanzas y Administración.

${ }^{1}$ En definitiva, asimilamos esta categoría a lo que se entiende por business administration en el contexto anglosajón

${ }^{2}$ Nuestro análisis del pensamiento administrativo en Argentina comienza en 1913, año en que se funda la FCE de la UBA. Naturalmente, hay desarrollos anteriores, vinculados fundamentalmente a la profesión de contador público, pero no los consideramos a los efectos de este trabajo.

${ }^{3}$ Los primeros atisbos de la aparición de la "izquierda revolucionaria" en Argentina se habían dado a fines de la década anterior. Véase, por ejemplo, Ollier (1998). Por otra parte, cabe señalar que dentro del movimiento peronista convivían con la izquierda sectores nacionalistas de extrema derecha, cuyas grupos paramilitares se dedicaban a combatir a ésta.

${ }^{4}$ En 1944 se publicó "Principios de Administración Cientìica" y un año después, "Administración de talleres". Esta última obra circulaba a través de ediciones españolas, la primera de las cuales data de 1914.

${ }^{5}$ Años después, Perel escribió otras obras de carácter similar. Por ejemplo, junto con otros profesores de su cátedra, publicó "La administración al alcance de casi todos" (Perel et. al., 1980).

${ }^{6}$ Cabe señalar que la tasa de desocupación alcanzó un máximo histórico en los noventa.

7 Por ejemplo, la UCA ofreció programas de doble titulación con la EOI de España, la Universidad de Belgrano dicta una maestría en Dirección Estratégica junto a Les Heures (Universidad de Barcelona) con la visita de profesores extranjeros, y otras instituciones tienen convenios de doble titulación con escuelas de negocios extranjeras que prevén la doble titulación de los alumnos que viajen al exterior para realizar cursos en tales instituciones (e.g., la Universidad Di Tella con el HEC de París).

${ }^{8}$ Es importante también señalar que en diversas universidades públicas del interior del país, los docentes a cargo de las asignaturas son, en muchos casos, profesores visitantes de universidades situadas en la ciudad de Buenos Aires, especialmente de la FCE de la UBA. 
Esto favorece a los "profesores estrella" de la capital, que complementan así sus ingresos viajando los fines de semana a dar cursos en el interior.

${ }^{9}$ Nos referimos a las presiones que puedan surgir a partir de los procesos de evaluación y acreditación de programas de posgrado y a los resultados de los rankings regionales de escuelas de negocios, en los cuales las instituciones argentinas no ocupan posiciones muy destacadas en comparación con sus pares de México, Brasil y Chile. En el ranking 2006 de la revista América Economía, por ejemplo, la posición más alta la ocupa el IAE con el puesto 8, seguido por la Universidad Torcuato Di Tella en el puesto 18.

${ }^{10}$ En este caso, Brugarola mezcla en Para ti, dirigente de empresa (1971) conceptos del cristianismo con la filosofía de gestión de Elton Mayo o Chester Barnard.

${ }^{11}$ Este sería un claro ejemplo de lo que Di Maggio y Powell (1983) denominan "isomorfismo mimético".

${ }^{12}$ De acuerdo a dicho estudio, tomando como referencia 2309 artículos publicados en revistas indexadas en el Social Sciences Citation Index durante el período 1994-2004, sólo el $21 \%$ podría considerarse dentro de la categoría administración de empresas, porcentaje que se reduce al $9 \%$ si se excluyen los articulos en publicaciones de marketing y aquellas de naturaleza multidisciplinaria. El $79 \%$ restante corresponde a publicaciones en economía, historia económica y finanzas. 